\title{
Hubungan Power Otot Lengan Koordinasi Mata Tangan dan Rentang Tangan dengan Hasil Servis Atas Pada Pemain Bola Voli Universitas Muhammadiyah Jakarta
}

\author{
M. Al Ghani ${ }^{1}$, Doby Parlindungan ${ }^{2}$, Ika Yulianingsih ${ }^{3}$ \\ Program Studi Pendidikan Olahraga, Universitas Muhammadiyah Jakarta \\ Kampus A, J1. KH Ahmad Dahlan, Ciputat, 15419, Indonesia \\ $\underline{\text { Algani17@gmail.com }}$
}

\begin{abstract}
ABSTRAK
Penelitian ini bertujuan untuk mengetahui hubungan power otot lengan, koordinasi mata tangan, dan rentang tangan dengan hasil servis atas pada pemain bola voli Universitas Muhammadiyah Jakarta. Metode yang digunakan dalam penelitian ini menggunakan desain korelasi. Populasi dalam penelitian ini yaitu seluruh pemain bola voli Universitas Muhammadiyah Jakarta berjumlah 20 orang dan sampel penelitian ini berjumlah 20 orang. Instrumen tes dalam penelitian ini yaitu tes medicine ball put, lempar tangkap bola tenis, tes rentang lengan dan tes servis bola atas. Teknik analisis data menggunakan SPSS statistik 20. Hasil penelitian menunjukkan dari hasil r1y adalah 0,625 berada pada interval 0,600-0,799, hubungan power otot lengan dengan servis atas adalah kuat. Hasil r2y adalah 0,511 berada pada interval 0,400-0,599, dapat disimpulkan bahwa hubungan koordinasi mata tangan dengan servis atas adalah sedang. Hasil r3y adalah 0,503 berada pada interval 0,400-0,599, hubungan rentang tangan dengan servis atas adalah sedang. Hasil r1,2,3y adalah 0,546 berada pada interval 0,400-0,599, dengan demikian dapat disimpulkan bahwa hubungan power otot lengan, koordniasi mata tangan dan rentang tangan dengan servis atas adalah sedang. Terdapat hubungan yang bersamaan power otot lengan, koordinasi mata tangan dan rentang tangan dengan hasil servis atas, nilai $\mathrm{F}_{\text {hitung }}$ lebih besar dari $\mathrm{F}_{\text {tabel }}$ yaitu 5,162 > 3,13.
\end{abstract}

Kata Kunci: power otot lengan, koordinasi mata tangan, rentang tangan, servis atas

ABSTRACT

This study aims to dtermine the correlation between arm muscle power, hand eye coordination, and hand span by overhand service University Muhammadiyah Of Jakarta players. The method used in this study uses a correlation design. The population in this study were all University Muhammadiyah Of Jakartavooley ball players totaling 20 players and the sample in this study amounted to 20 players. The instruments in this research used medicine ball put, fetch tennisball, arm length test aand overhand servis test. The result show rly yield is 0.625 is at intervals of 0.600-0.799, arm muscle power relationship with overhand service is strong. The r2y result is 0.511 is at intervals of 0.400-0.599, it can be concluded that the corelation of hand eye coordination with overhand service is moderate. The r3y result is 0.503 at intervals of 0.400-0.599, hand range relationship with top service is moderate. The result r1,2,3y is 0.546 is at intervals of 0.400-0.599, thus it can be concluded that the power relationship of the arm muscles, co-ordinated eye and hand range with overhand service is moderate. There is a concurrent correlation of arm muscle power, hand eye coordination and hand range with overhand service results, the value of $F$ count $>F$ table that is 5,162 > 3.13.

Keywords: arm muscle power, hand eye coordination, arm length, overhand service

Dipublikasikan Oleh :

UPT Publikasi dan Pengelolaan Jurnal

Universitas Islam Kalimantan Muhammad Arsyad Al-Banjari Banjarmasin 


\section{PENDAHULUAN}

Olahraga memiliki peranan yang cukup sentral dalam proses pembangunan manusia Indonesia melalui jalur pendidikan. Dalam Undang-Undang Sistem Keolahragaan Nasional (SKN) nomor 3 tahun 2005 telah dijelaskan dengan sangat jelas pada bab I bahwa olahraga dalam persepektif pendidikan jasmani dilaksanakan sebagai bagian dari proses pendidikan yang teratur dan berkelanjutan untuk memperoleh pengetahuan, kepribadian, keterampilan, kesehatan dan kebugaran jasmani.

Perkembangan fisik dan mental peserta didik dalam proses pendidikan dijadwalkan melalui berbagai macam pengenalan dan pembelajaran beberapa cabang olahraga. Permainan bola voli memang salah satu permainan yang dapat membuat orang yang melakukannya senang dan terampil dalam bergerak. Latihan bola voli menekankan agar pemain dapat menguasai keterampilan bermain, kenyataannya banyak pemain belum mampu melakukan teknik-teknik bermain bola voli sehingga permainan bola voli terkesan monoton. (Islam, Muhammad, Al, Banjarmasin, \& Reaksi, n.d.) Selain itu masih ada faktor lain yang mempengaruhi kecepatan reaksi yaitu faktor fisik, faktor internal dan faktor eksternal. Faktor fisik terdiri dari kelincahan, Koordinasi Neuromuscular, dan keseimbangan. Kemudian faktor internal terdiri dari genetik, tipe tubuh, usia, jenis kelamin, berat badan, kelelahan, dan motivasi sedangkan faktor eksternal terdiri dari, keadaan diluar, suasana lingkungan, fokus.

Permainan bola voli tidak hanya diajarkan melalui pembelajaran pendidikan jasmani, lebih dari itu beberapa Universitas biasanya membentuk tim untuk membantu para mahasiswa tidak hanya dari sisi prestasi belajar, melainkan prestasi dalam cabang olahraga boli voli. Salah satu Universitas yang memiliki tim bola voli adalah Universitas Muhammadiyah Jakarta. Berdasarkan pantauan melalui observasi di lapangan, terdapat beberapa pemain yang belum terampil dalam teknik-teknik bermain voli. Hal itu salah satunya dibuktikan ketika pemain melakukan servis atas bola voli. Servis atas yang baik harus ditunjang dengan ayunan lengan yang baik, tidak hanya ayunan melainkan ketepatan dalam melakukan pukulan terhadap sasaran mana yang diinginkan oleh pemain juga mendukung dalam melakukan servis yang baik. Hal tersebut tidak mudah dilakukan oleh pemain bola voli Universitas Muhammadiyah Jakarta, terbukti dalam beberapa sasaran yang ditetapkan oleh pelatih hanya beberapa siswa yang mampu melakukannya dengan benar. Dari 20 orang pemain bola voli sebanyak 5 orang sudah memiliki kemampuan servis atas yang baik dan sisanya 15 orang belum memiliki kemampuan servis atas yang baik, hal tersebut dibuktikan dengan bola yang melambung jauh keluar lapangan, bola menyangkut di net dan arah bola terlalu mudah untuk di tebak lawan. (E Pratiwi, A Barikah, 2020)

Servis adalah kemampuan seorang pemain dalam memukul bola pertama kali saat permainan akan dilakukan atau ketika pemain hendak memperoleh poin dari set yang telah dijalankan. Servis atas dilakukan lewat pukulan dari atas kepala. Servis ini sangat membutuhkan power otot lengan dan koordinasi mata-tangan. Disamping power otot lengan servis juga bergantung dengan rentang tangan yang dimiliki setiap pemain, biasanya pemain yang memiliki rentangan tangan cukup panjang akan lebih mudah merekayasa arah bola. Tanpa power lengan, koordinasi mata-tangan dan rentang tangan yang baik servis ini tidak akan tertuju pada sasaran yang diinginkan. Apalagi siswa tergolong pemain voli pemula sehingga sangat sulit servis atas dilakukan tanpa bantuan power otot lengan, koordinasi mata-tangan dan rentang tangan (Winarno, 2014: 83).

Power lengan adalah jenis skil fitnes yang bersumber dari hentakan otot lengan. Ayunan yang dimaksud adalah kekuatan dan kecepatan. Koordinasi mata-tangan merupakan rangkaian gerak yang melibatkan beberapa syaraf otot untuk berkoordinasi menjadi satu kesatuan gerak yang utuh. Sementara rentang tangan adalah panjang tangan yang dihitung dari pangkal otot deltoid dan berakhir pada ujung jari. Servis atas dalam permainan bola voli adalah servis yang dilakukan dengan gerakan lengan, hentakan menjadi kunci, gerakan mata dan tangan menjadi penentu untuk menentukan arah sasaran, sementara rentang lengan membantu memberikan kemudahan pada bola ketika dipukul. Sehingga saat servis atas dilakukan semakin baik power otot lengan, koordinasi mata-tangan dan rentang tangan yang dimiliki pemain maka semakin baik pula servis atas pemain itu sendiri.

\section{METODE}

Secara umum metode penelitian diartikan sebagai cara ilmiah untuk mendapatkan data dengan tujuan dan kegunaan tertentu (Sugiyono 2012). Metode yang digunakan adalah metode kolerasional dengan tujuan mencari ada hubungan yang signifikan power otot lengan, koordinasi mata-tangan dan rentang dengan hasil servis atas pada pemain bola voli Universitas Muhammadiyah Jakarta.

Servis atas adalah servis yang dilakukan dengan cara memukul bola dengan jari-jari tangan yang terbuka dan rapat, serta bola dipukul menggunakan telapak tangan. Bola yang dipukul pun harus dilambungankan dengan tinggi diatas kepala dan dipukul sebelum melewati kepala. (Mulyadi Dwi dan Pratiwi Endang, 2020)

Dipublikasikan Oleh :

UPT Publikasi dan Pengelolaan Jurnal

Universitas Islam Kalimantan Muhammad Arsyad Al-Banjari Banjarmasin 


\section{Rancangan Penelitian}

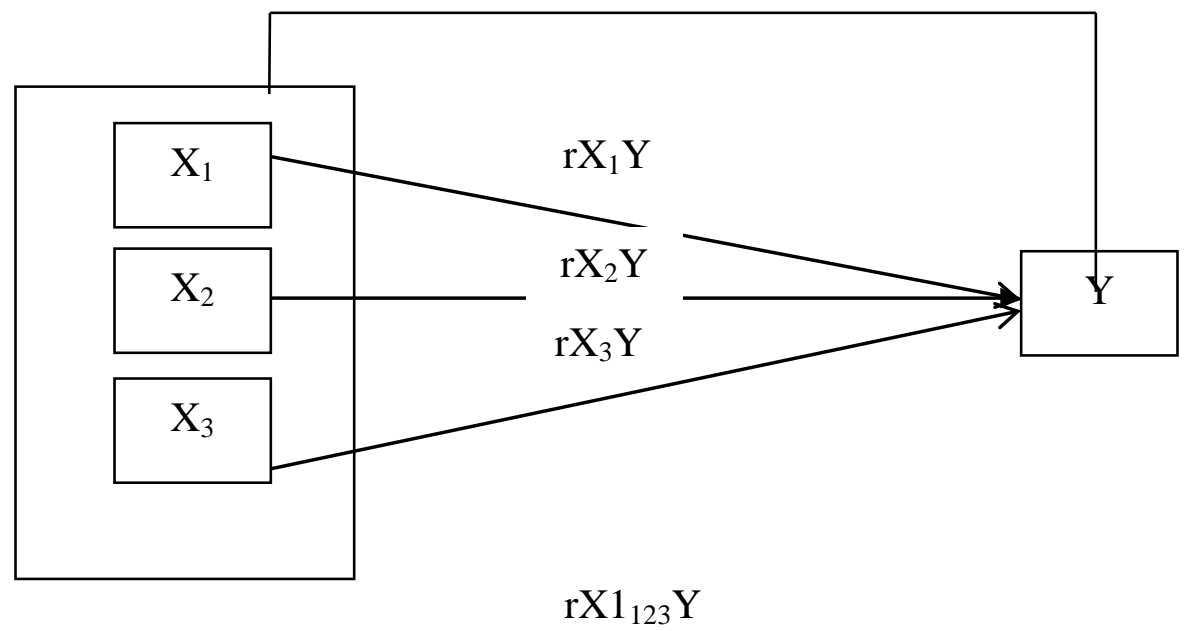

Gambar .1 Rancangan Penelitian

(Sumber: Sugiyono, 2012)

Keterangan :

$\begin{array}{ll}\text { X1 } & =\text { Power otot lengan } \\ \text { X2 } & =\text { Koordinasi mata-tangan } \\ \text { X3 } & =\text { Rentang tangan } \\ \text { Y } & =\text { Hasil Servis Atas }\end{array}$

Tempat dan Waktu Penelitian

Penelitian dilakukan di lapangan Universitas Muhammadiyah Jakarta. Waktu penelitian dilakukan hari Jum'at, Sabtu dan Minggu pada pukul 16.00 WIB - 18.00 WIB.

\section{POPULASI DAN SAMPEL}

Populasi adalah keseluruhan subjek penelitian. Adapun yang menjadi populasi dalam penelitian ini adalah peserta sekolah sepak bola Senuro. Populasi adalah keseluruhan subjek penelitian, (Arikunto, 2006: 130). Keseluruhan yang menjadi sasaran dalam penelitiah ini adalah pemain sepakbola Universitas Bina Darma yang berjumlah 17 orang. Arikunto (2006: 131) mengatakan bahwa sampel adalah sebagian atau wakil populasi yang diteliti. "Untuk sekedar ecer-ecer, maka apabila subjeknya kurang dari 100, maka lebih baik diambil semua sehingga penelitiannya merupakan penelitian populasi. Tetapi, jika jumlah subjeknya besar, dapat diambil antara $10-15 \%$ atau $20-25 \%$ atau lebih". Berdasarkan pendapat ahli di atas maka sampel yang diambil dalam penelitian ini adalah pemain bola voli Universitas Muhammadiyah Jakarta yang berjumlah 20 orang.

\section{INSTRUMEN TES}

\section{Instrument Tes Power Otot Lengan}

Adapun langkah-langkah pelaksanaan tes medicine ball throw dpaat dijelaskan sebagai berikut :

1 Nama Test

2 Sumber

3 Tujuan Tes

4 Alat/fasilitas

5 Pelaksanaan tes
: Instrumen tes pada variabel bebas (X) dalam penelitian ini adalah Two Hand Medicine Ball Trouwh (Ismaryati, 2008: 64).

: Tes ini bertujuan untuk mengukur gerak eksplosif tubuh : (lengan).

1. Bola medicine seberat $2,72 \mathrm{~kg}$

: 2. Kapur atau isolasi.

3. Formulir pencatat hasil

4. Bangku dan meteran

1. Testee berdiri dengan punggung lurus

2. Testee memegang bola medicine degan kedua tangan diatas kepala.

3. Testee melempar bola kedepan sejauh mungkin.

Dipublikasikan Oleh : 

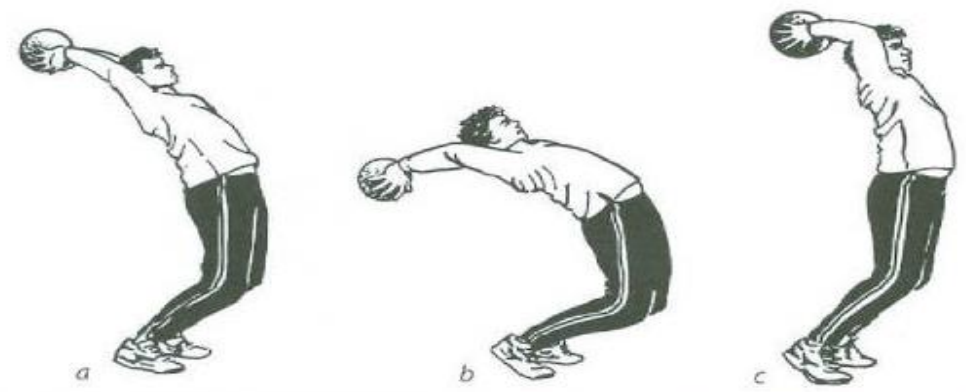

Gambar 2 Tata Cara Pelaksanaan Tes

(Sumber : Ismaryati, 2008)

Tabel 1. Norma Penilaian

\begin{tabular}{|c|c|c|}
\hline No & Interval Nilai & Keterangan \\
\hline 1 & $<3$ Meter & Kurang Sekali \\
\hline 2 & $3,01-5$ Meter & Kurang \\
\hline 3 & $5,01-10$ Meter & Cukup \\
\hline 4 & $>10,01$ & Baik \\
\hline
\end{tabular}

(Sumber : Kemenpora, 2014)

\section{Instrument Tes Koordinasi Mata Tangan}

Kemenpora (2014: 33) menjelaskan tes koordinasi mata-tangan dapat menggunakan tes lempar tangkap bola tennis dengan rincian sebagai berikut : (Supriatna, 2017)
a. Nama Tes
: Lempar Tangkap Bola Tenis
b. Tujuan Tes
: Untuk mengukur koordinasi mata-tangan
c. Perlengkapan
: Bola Tenis dan Tembok Sasaran.

d. Pelaksanan

:

1) Dengan satu tangan dan ditangkap dengan tangan lainnya.

2) Sebelum melakukan tes, testee boleh melakukan terlebih dahulu sampai merasa terbiasa.

3) Beri tanda dengan sebuah garis atau lantai berjarak 2,5 meter dan sasaran bundar (warna hitam) pada diding diameter $30 \mathrm{~cm}$.

4) Tiap teste diberi kesempatan 10 kali untuk melempar dan menangkap dengan tangan yang disukai, kemudian diikuti dengan 10 kali kesempatan untuk melempar dengan tangan yang disukai dan menangkap dengan tangan yang lain.

e. Penilaian

1) Tiap lemparan yang mengenai sasaran dan tertangkap tangan memperoleh nilai satu.

2) Untuk memperoleh nilai maka, bola harus dilemparkan dari arah bawah (underarm).

3) Bola harus mengenai sasaran.

4) Testee tidak beranjak atau berpindah keluar garis batas menangkap bola.

5) Jumlah nilai hasil 10 lemparan pertama dan 10 lemparan kedua. Nilai total yang mungkin dicapai adalah 20.

Tabel 2. Norma Penilaian

\begin{tabular}{|c|c|c|}
\hline No & Interval Nilai & Keterangan \\
\hline 1 & $<5$ & Kurang Sekali \\
\hline 2 & $6-10$ & Kurang \\
\hline 3 & $11-15$ & Cukup \\
\hline 4 & $>16$ & Baik \\
\hline
\end{tabular}

Dipublikasikan Oleh :

UPT Publikasi dan Pengelolaan Jurnal

Universitas Islam Kalimantan Muhammad Arsyad Al-Banjari Banjarmasin 


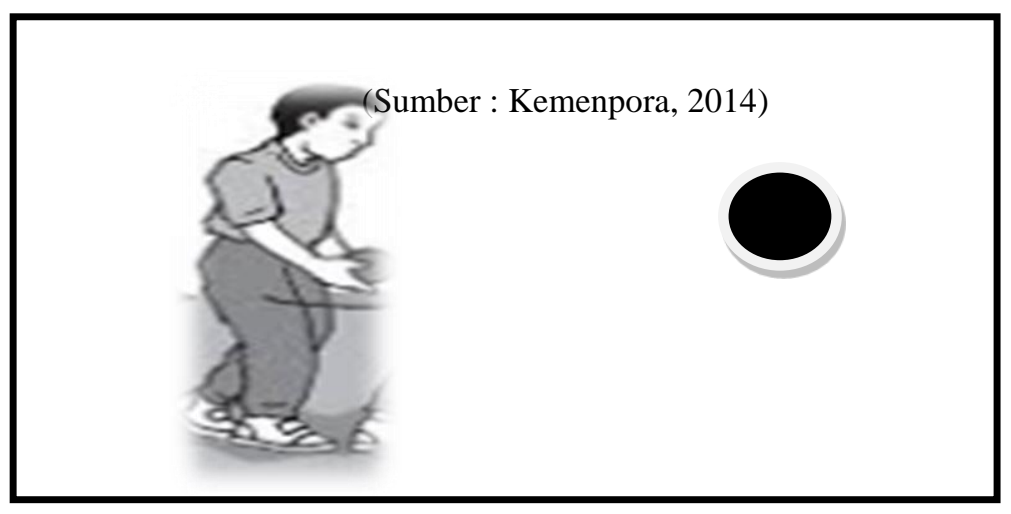

Gambar 3. Lempar Tangkap Bola Tennis

(Sumber : Kemenpora, 2014)

\section{Instrumen Tes Rentang Lengan}

Pengukuran rentang tangan dapat dilakukan dengan keadaan testi berdiri dengan posisi anatomi pada lantai yang datar tanpa mengenakan alas kaki. Panjang lengan diukur dari acromion sampai ujung jari tengah. Agar lebih jelas pengukuran rentang tangan dapat dilihat pada gambar 5 dibawah ini :

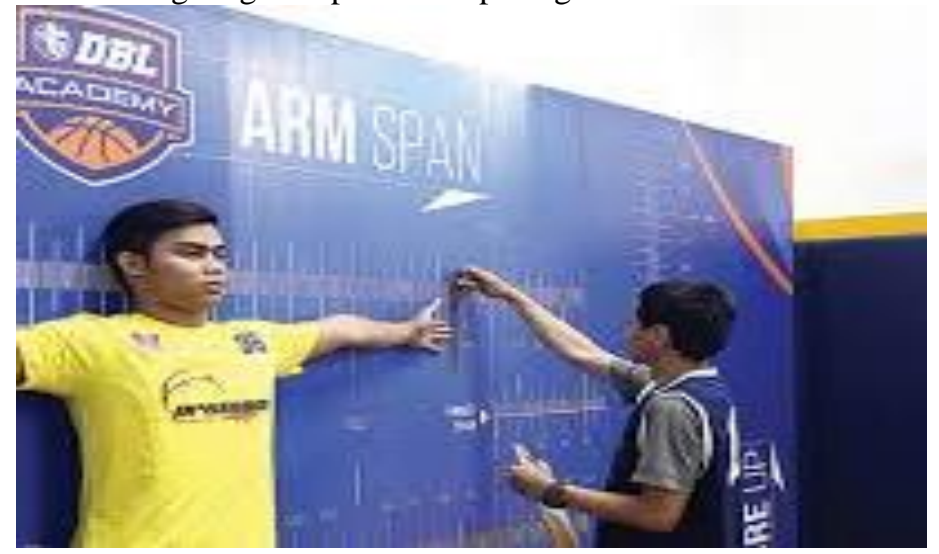

Gambar.4. Pengukuran Rentang Tangan

\section{Instrumen Tes Servis Atas Bola Voli}

(Sumber : Ismaryati, 2010)

Tes servis atas bola voli akan dijabarkan rinciannya sebagai berikut :
a) Nama Tes
b) Tujuan Tes
c) Sumber
d) Fasilitas/alat

e) Petunjuk Pelaksanaan
: Intstrumen tes variabel (Y) tes hasil servis atas bola voli

: Untuk mengukur hasil servis atas bola voli

(Nurhasan, 2000: 213)

: 1. Lapangan dan aera penilaian servis bola voli

2. Bola voli

3. Peluit

4. Alat-alat tulis dan format pengambilan data

5. Petugas pencatat 1 orang

: 1. Sebelum melakukan tes, testee berdiri dengan bola di belakang garis servis.

2. Setelah aba-aba peluit dibunyikan testee melakukan servis atas untuk memukul bola menuju sasaran nilai yang telah ditentukan.

3. Testee diberikan kesempatan memukul bola sebanyak 5 pukulan.

4. Skor ditentukan oleh jumlah bola yang mampu masuk ke dalam area nilai. Kemungkinan terbaik skor yang dapat diperoleh adalah 25 point. 


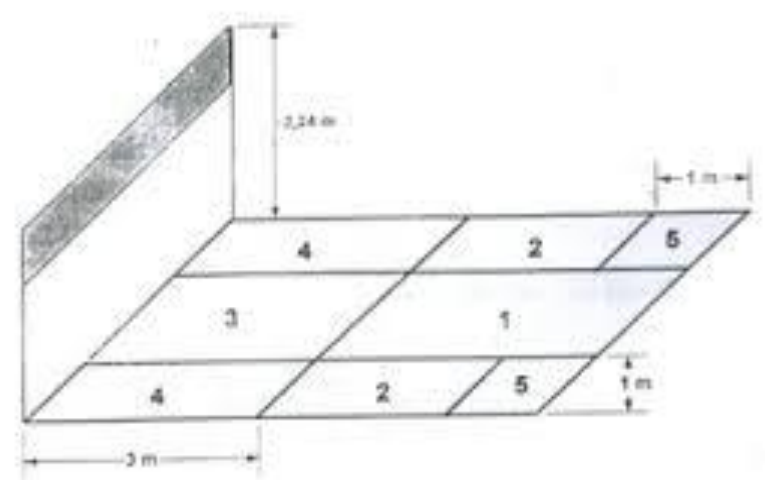

Gambar 5.. Lapangan Tes Servis

(Sumber : Nurhasan, 2000)

Tabel 3. Norma Tes Servis Atas

\begin{tabular}{|c|c|c|}
\hline No & Interval Nilai & Keterangan \\
\hline 1 & $<5$ & Kurang Sekali \\
\hline 2 & $6-10$ & Kurang \\
\hline 3 & $11-20$ & Cukup \\
\hline 4 & $>21$ & Baik \\
\hline
\end{tabular}

(Sumber : Nurhasan, 2000)

HASIL DAN PEMBAHASAN

a. Hipotesis Power Otot Lengan dengan Servis Atas $\left(\mathrm{X}_{1} \mathrm{Y}\right)$

Tabel 4. Model Summary

\begin{tabular}{|l|r|r|r|c|}
\hline Model & R & R Square & \multicolumn{1}{|c|}{$\begin{array}{c}\text { Adjusted R } \\
\text { Square }\end{array}$} & $\begin{array}{c}\text { Std. Error of the } \\
\text { Estimate }\end{array}$ \\
\hline 1 & $.625^{\mathrm{a}}$ & .391 & .357 & 1.52606 \\
\hline
\end{tabular}

a. Predictors: (Constant), Power otot lengan

Berdasarkan hasil uji r (product moment) secara parsial di atas dengan SPSS 20 dapat disimpulkan bahwa hasil $r_{1} y$ adalah 0,625 berada pada interval 0,600-0,799 dengan tingkat hubungan kuat. Dengan demikian dapat disimpulkan bahwa hubungan power otot lengan dengan servis atas adalah kuat.

\section{b. Hipotesis Koordinasi Mata Tangan dengan Servis Atas $\left(\mathrm{X}_{2} \mathrm{Y}\right)$}

Tabel 5. Model Summary

\begin{tabular}{|l|r|r|r|c|}
\hline Model & \multicolumn{1}{|c|}{$\mathrm{R}$} & R Square & \multicolumn{1}{c|}{$\begin{array}{c}\text { Adjusted R } \\
\text { Square }\end{array}$} & $\begin{array}{c}\text { Std. Error of the } \\
\text { Estimate }\end{array}$ \\
\hline 1 & $.511^{\mathrm{a}}$ & .262 & .221 & 1.67998 \\
\hline
\end{tabular}

a. Predictors: (Constant), Koordinasi mata-tangan

Berdasarkan hasil uji r (product moment) secara parsial di atas dengan SPSS 20 dapat disimpulkan bahwa hasil $r_{2} y$ adalah 0,511 berada pada interval 0,400-0,599 dengan tingkat hubungan sedang. Dengan demikian dapat disimpulkan bahwa hubungan koordinasi mata-tangan dengan servis atas adalah sedang

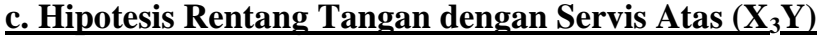

Tabel 6. Model Summary

\begin{tabular}{|l|r|r|r|c|}
\hline Model & R & R Square & \multicolumn{1}{c|}{$\begin{array}{c}\text { Adjusted R } \\
\text { Square }\end{array}$} & $\begin{array}{c}\text { Std. Error of the } \\
\text { Estimate }\end{array}$ \\
\hline 1 & $.503^{\mathrm{a}}$ & .253 & .212 & 1.68934 \\
\hline
\end{tabular}

Dipublikasikan Oleh :

UPT Publikasi dan Pengelolaan Jurnal

Universitas Islam Kalimantan Muhammad Arsyad Al-Banjari Banjarmasin 
Tabel 6. Model Summary

\begin{tabular}{|l|r|r|r|c|}
\hline Model & \multicolumn{1}{|c|}{$\mathrm{R}$} & R Square & \multicolumn{1}{c|}{$\begin{array}{c}\text { Adjusted R } \\
\text { Square }\end{array}$} & $\begin{array}{c}\text { Std. Error of the } \\
\text { Estimate }\end{array}$ \\
\hline 1 & $.503^{\mathrm{a}}$ & .253 & .212 & 1.68934 \\
\hline
\end{tabular}

a. Predictors: (Constant), Rentang lengan

Berdasarkan hasil uji r (product moment) secara parsial di atas dengan SPSS 16 dapat disimpulkan bahwa hasil $r_{3} y$ adalah 0,503 berada pada interval 0,400-0,599 dengan tingkat hubungan sedang. Dengan demikian dapat disimpulkan bahwa hubungan rentang tangan dengan servis atas adalah sedang.

\section{UJI F SIMULTAN}

\section{a. Hipotesisi Power Otot Lengan, Koordinasi Mata-Tangan dan Rentang Lengan Dengan Servis Atas (Korelasi Ganda)}

Tabel 7. Model Summary

\begin{tabular}{|l|r|r|r|c|}
\hline Model & R & R Square & \multicolumn{1}{|c|}{$\begin{array}{c}\text { Adjusted R } \\
\text { Square }\end{array}$} & $\begin{array}{c}\text { Std. Error of the } \\
\text { Estimate }\end{array}$ \\
\hline 1 & $.546^{\mathrm{a}}$ & .253 & .212 & 1.68934 \\
\hline
\end{tabular}

a. Predictors: (Constant), Power Otot Lengan,

Koordinasi, Rentang lengan

Berdasarkan hasil uji r (korelasi ganda) secara parsial di atas dengan SPSS 16 dapat disimpulkan bahwa hasil $\mathrm{R}$ adalah 0,546 berada pada interval 0,400-0,599 dengan tingkat hubungan sedang. Dengan demikian dapat disimpulkan bahwa hubungan power otot lengan, koordinasi mata-tangan dan rentang tangan dengan servis atas adalah sedang.

\section{b. Uji Siginifikasi}

Uji F simultan dimaksudkan untuk menguji hipotesis ganda yaitu hubungan secara bersamaan power otot lengan, koordinasi mata-tangan dan rentang tangan dengan hasil servis atas. Adapun hasil uji $\mathrm{F}$ simultan dapat dilihat pada tabel di bawah ini :

Tabel 8. ANOVA ${ }^{b}$

\begin{tabular}{|rl|r|r|r|r|r|}
\hline Model & Sum of Squares & df & Mean Square & F & \multicolumn{1}{c|}{ Sig. } \\
\hline & Regression & 33.838 & 3 & 11.279 & 5.162 & $.011^{\mathrm{a}}$ \\
Residual & 34.962 & 16 & 2.185 & & \\
Total & 68.800 & 19 & & & \\
\hline
\end{tabular}

a. Predictors: (Constant), Rentang lengan, Power otot lengan , Koordinasi mata-tangan

b. Dependent Variable: Servis atas

Berdasarkan tabel di atas dapat disimpulkan bahwa nilai fhitung lebih besar dari ftabel yaitu 5,162 > 3,13 , artinya terdapat hubungan yang bersamaan power otot lengan, koordinasi mata-tangan dan rentang tangan dengan hasil servis atas pada pemain bola voli Universitas Muhammadiyah Jakarta

\section{PEMBAHASAN}

Berdasarkan hasil penelitian dan uji hipotesis yang telah dilakukan, penelitian ini dinyatakan bahwa :

a. Hasil $r_{1}$ y adalah 0,625 berada pada interval 0,600-0,799 dengan tingkat hubungan kuat. Dengan demikian dapat disimpulkan bahwa hubungan power otot lengan dengan servis atas adalah kuat.

b. Hasil $\mathrm{r}_{2} \mathrm{y}$ adalah 0,511 berada pada interval 0,400-0,599 dengan tingkat hubungan sedang. Dengan demikian dapat disimpulkan bahwa hubungan koordinasi mata-tangan dengan servis atas adalah sedang.

c. Hasil $r_{3} y$ adalah 0,503 berada pada interval 0,400-0,599 dengan tingkat hubungan sedang. Dengan demikian dapat disimpulkan bahwa hubungan rentang tangan dengan servis atas adalah sedang.

d. Hasil $\mathrm{r}_{1,2,3} \mathrm{y}$ adalah 0,546 berada pada interval 0,400-0,599 dengan tingkat hubungan sedang. Dengan demikian dapat disimpulkan bahwa hubungan power otot lengan, koordinasi mata-tangan dan rentang tangan dengan servis atas adalah sedang.

Dipublikasikan Oleh :

UPT Publikasi dan Pengelolaan Jurnal

Universitas Islam Kalimantan Muhammad Arsyad Al-Banjari Banjarmasin 
e. Nilai $\mathrm{f}_{\text {hitung }}$ lebih besar dari $\mathrm{f}_{\text {tabel }}$ yaitu $5,162>3,13$, artinya terdapat hubungan yang bersamaan power otot lengan, koordinasi mata-tangan dan rentang tangan dengan hasil servis atas pada pemain bola voli Universitas Muhammadiyah Jakarta.

Melihat dari hasil di atas, ketiga variabel bebas sama-sama memiliki hubungan terhadap hasil servis atas, tetapi dari ketiganya dapat disimpulkan bahwa power otot lengan memiliki hubungan yang kuat dari keduanya yaitu koordinasi dan rentang lengan. Hasil tersebut menunjukan bahwa power otot lengan adalah komponen biomotor yang sangat penting dalam melakukan servis atas disamping kedua komponen biomotor seperti koordinasi dan rentang lengan.

\section{PENUTUP}

\section{KESIMPULAN}

Berdasarkan hasil penelitian dan uji hipotesis, penelitian ini memberikan kesimpulan bahwa :

1. Hubungan power otot lengan dengan servis atas pemain bola voli Universitas Muhammadiyah Jakarta adalah kuat.

2. Hubungan koordinasi mata-tangan dengan servis atas pemain bola voli Universitas Muhammadiyah Jakarta adalah sedang.

3. Hubungan rentang tangan dengan servis atas pemain bola voli Universitas Muhammadiyah Jakarta adalah sedang.

4. Hubungan power otot lengan, koordinasi mata-tangan dan rentang tangan dengan servis atas pemain bola voli Universitas Muhammadiyah Jakarta adalah sedang.

5. Terdapat hubungan yang bersamaan power otot lengan, koordinasi mata-tangan dan rentang tangan dengan hasil servis atas pada pemain bola voli Universitas Muhammadiyah Jakarta.

\section{SARAN}

Berdasarkan hasil penelitian di atas, beberapa hal yang perlu disarankan adalah sebagai berikut :

1. Bahwa pemain harus rajin dan giat berlatih khususnya melatih power otot lengan, koordinasi mata-tangan dan rentang tangan agar dapat meningkatkan kemampuan servis atas.

2. Bahwa pelatih agar dapat memberikan menu latihan khusus seperti power otot lengan, koordinasi matatangan dan rentang lengan.

3. Agar pihak universitas dapat memfasilitas sarana dan prasarana latihan ekstrakuriler bola voli.

\section{REFERENSI}

Arikunto, Suharsimi. 2006. Proedur Penelitian. Jakarta: Rineka Cipta.

Ismaryati. (2008). Tes \& Pengukuran Olahraga. Surakarta: UNS Press.

Ismaryati. (2010). Tes \& Pengukuran Olahraga. Surakarta: UNS Press

Nurhasan, 2000. Tes dan pengukuran pendidikan olahraga.fakultas pendidikan dan kesehatan universitas pendidikan Indonesia.

Sugiyono, 2012. Metode Penelitian Pendidikan Pendekatan Kuantitatif, Kualitatif dan R\&D.

CV Alfabeta. Bandung.

Winarno. 2014. Hubungan Koordinasi mata-tangan dengan hasil servis bola voli. Universitas Negeri Malang.

E Pratiwi, A Barikah, N. A. (2020). Jurnal. Olympia Binadarma, 2, 1-7. Retrieved from http://journal.binadarma.ac.id/index.php/olympia/article/view/881

Islam, U., Muhammad, K., Al, A., Banjarmasin, B., \& Reaksi, K. (n.d.). UPT Publikasi dan Pengelolaan Jurnal Universitas Islam Kalimantan Muhammad Arsyad Al-Banjari Banjarmasin UPT Publikasi dan Pengelolaan Jurnal Universitas Islam Kalimantan Muhammad Arsyad Al-Banjari Banjarmasin. Analisis Kecepatan Reaksi, 1-8. Retrieved from https://ojs.uniska-bjm.ac.id/index.php/riyadhohjurnal/article/view/2024/1673

Mulyadi Dwi dan Pratiwi Endang. (2020). Buku Pembelajaran BolaVoli. In Norma Anggara dan Novri (Ed.), Pembelajaran Bola Voli (pp. 11-12).

Supriatna, E. (2017). Pemanduan Bakat Olahraga. Performa Olahraga, 2(01), 55-68.

Dipublikasikan Oleh :

UPT Publikasi dan Pengelolaan Jurnal

Universitas Islam Kalimantan Muhammad Arsyad Al-Banjari Banjarmasin 